\title{
OPEN Using past interglacial temperature maxima to explore transgressions in modern Maldivian coral and Amphistegina bleaching thresholds
}

\author{
Stephanie Stainbank ${ }^{1 \bowtie}$, Dick Kroon ${ }^{2}$, Erica S. de Leau² \& Silvia Spezzaferri ${ }^{1}$
}

Tropical corals and Amphistegina, an example genus of symbiont-bearing larger benthic foraminifera, are presently living close to their thermal bleaching thresholds. As such, these essential reefbuilding organisms are vulnerable to the future prospect of more frequent sea surface temperature (SST) extremes. Exploring the earth's paleo-climatic record, including interglacials warmer than present, may provide insights into future oceanographic conditions. We analyse foraminiferal shell geochemical compositions, from Recent surface sediments and Marine Isotope stage (MIS) 9e and MIS11c aged sediments, from the International Ocean Discovery Program Expedition 359 Site U1467 drilled in the Inner Sea of the Maldives. We illustrate through traditional (pooled) geochemical analysis $\left(\delta^{18} \mathrm{O}, \mathrm{Mg} / \mathrm{Ca}\right)$ that tropical temperatures were indeed marginally warmer during MIS9e and MIS11c in comparison to the modern ocean. Individual foraminiferal analysis (IFA) from the Recent (representing the last few hundred years) and MIS9e samples shows SSTs occasionally breached the coral bleaching threshold similarly to the modern-day. Significantly, the number of transgressions was four times higher during MIS11c, a recognised analogue for a warmer modern world. This new knowledge and novel IFA insight and application is invaluable given thermal stress is already obvious today with an increasing number of bleaching events over the last few decades.

It is undisputed that the future resilience, ecological functioning and ultimate survival of the world's coral reefs is threatened ${ }^{1,2}$. These globally distributed tropical/subtropical ecosystems are biodiversity hotspots and fundamental socioeconomic components for innumerable countries, many of which already have extensive long-term monitoring and restoration programs in place $^{3}$ (Fig. 1a). Due to the current sea surface temperature (SST) warming trends ${ }^{4}$, essential symbiont-bearing reef dwelling organisms are vulnerable. Both corals, the building blocks of reefs, and larger benthic foraminifera $(\sim>500 \mu \mathrm{m})$ are important symbiont-bearing reef sediment contributors ${ }^{5}$. Considering their sensitivity to climatic perturbations, exemplified by the increase in duration and frequency of bleaching events over the last few decades, gaining insights into possible future scenarios is paramount. Looking within the earth's paleo-climatic record could provide plausible future scenarios and extensive studies have identified multiple prospective analogues for our current Marine Isotope Stage 1 (MIS1) (e.g., MIS5e, 9e, 11c, 196,7).

The reef-building Scleractinian corals, marine invertebrates that secrete calcium carbonate (aragonite) skeletons, have a mutualistic relationship with microalgae symbionts (zooxanthellae) which are essential to their survival $^{8,9}$ (Fig. 2). Similarly, Amphistegina, a larger benthic foraminifera (unicellular protist: $\sim 500 \mu \mathrm{m}-3 \mathrm{~mm}$ ) that secretes a calcium carbonate (calcite) shell (test), has a mutualistic relationship with its symbionts (diatoms) ${ }^{5}$ (Fig. 2). Under high SSTs, these organisms become stressed and are susceptible to bleaching, which implies either the expulsion or digestion of their symbionts leaving them with a characteristic white appearance ${ }^{8,9}$ (Fig. 2). Over prolonged and/or more frequent warm events (e.g., El Niño events), the potential for corals and Amphistegina to recover diminishes, which can lead to high mortality events and even the ultimate demise of entire reefs, as seen globally in the El Niño related mass-bleaching's of 1998, 2010 and 2016. As such, assessing transgressions in bleaching thresholds is important to aid in our understanding of these fragile biologically and economically

${ }^{1}$ Department of GeoSciences, University of Fribourg, Chemin du Musée 6, 1700 Fribourg, Switzerland. ${ }^{2}$ School of GeoSciences, Grant Institute, University of Edinburgh, The King's Buildings, James Hutton Road, Edinburgh EH9 3FE, United Kingdom. ${ }^{\boxplus}$ email: stephaniehayman.23@gmail.com 

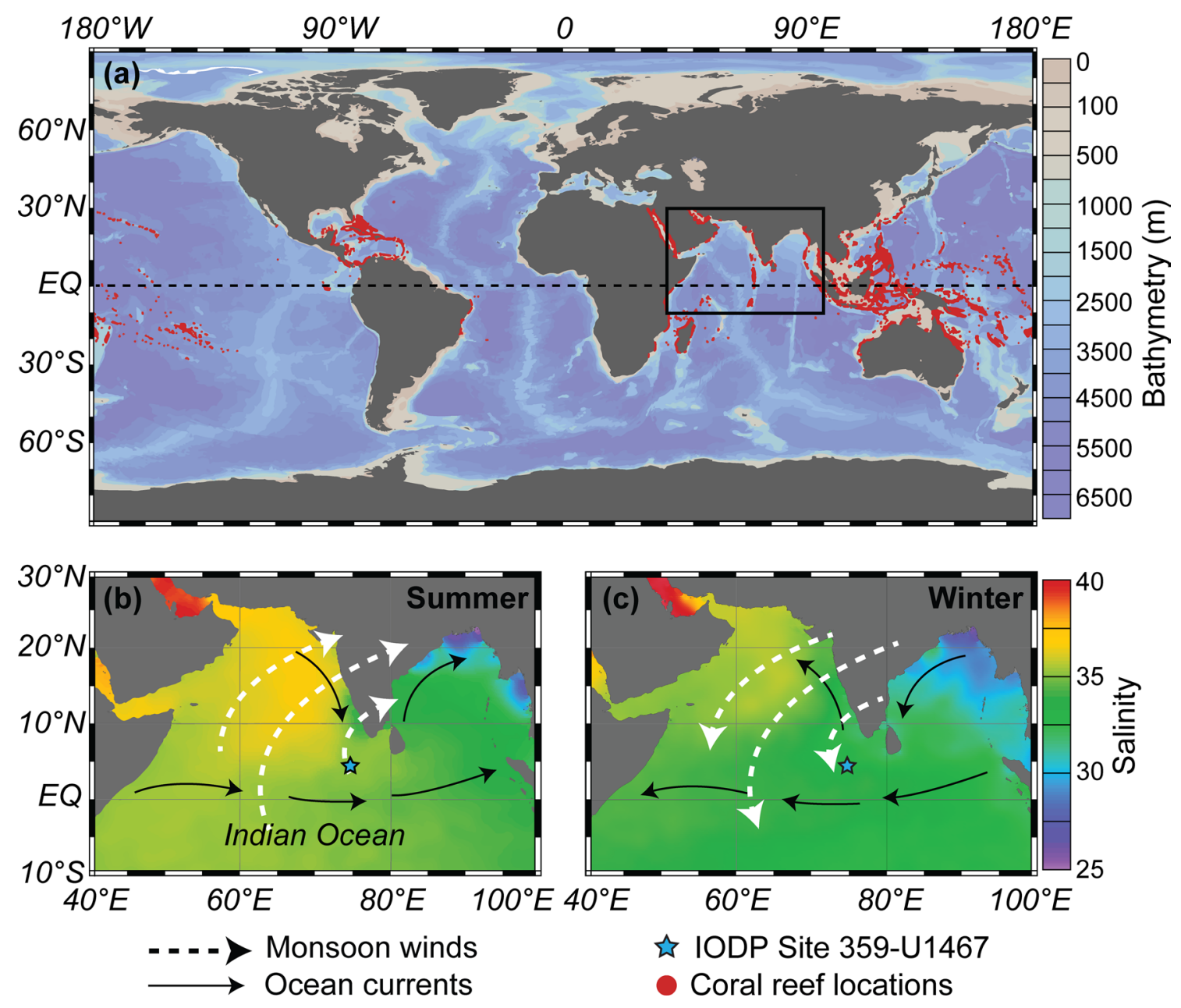

Figure 1. Global coral reef distribution and study area maps. (a) Global distribution of coral reefs (red dots) with the northern Indian Ocean salinity conditions shown for (b) summer and (c) winter. South Asian Monsoon wind (dashed arrows) and surface current (solid arrows) directions are indicated, with the location of the study site (IODP359-U1467 ${ }^{19}$ ) marked by the blue star (coral reef locations from ${ }^{61}$ and all maps produced using Ocean data Viewer ${ }^{62,63}$ ).

(a) Bleached populations

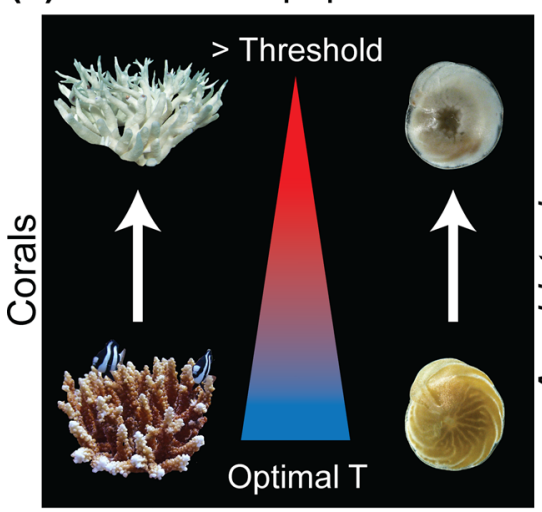

Healthy populations (b)

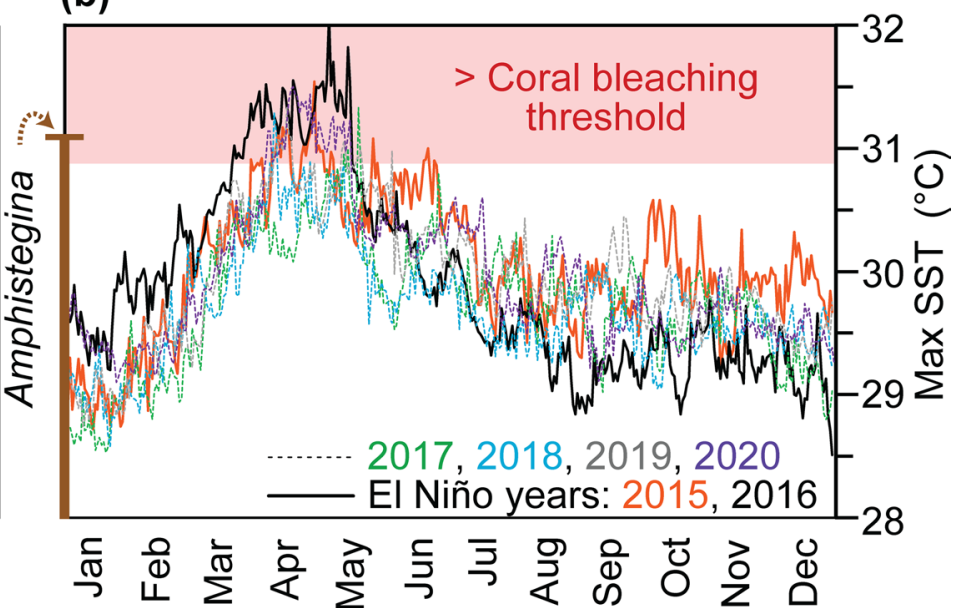

Figure 2. Bleaching thresholds. (a) Bleaching schematic for corals and the larger benthic foraminifera Amphistegina together with (b) maximum (Max) sea surface temperatures (SSTs) recorded in the Maldives for the years $2015-2020^{10}$. El Niño years (2015 and 2016) are represented by the solid lines with the years 2017-2020 represented by dashed lines. Temperatures $>$ the coral bleaching threshold for the Maldivian coral reefs $\left(\sim 30.9^{\circ} \mathrm{C}^{10,25}\right)$ are indicated in red shading. $\delta^{18} \mathrm{O}_{c}$ temperature estimates derived from living (Rose Bengal stained) Amphistegina lessonii, from the Maldives, are also shown (vertical brown line). 
significant ecosystems. Coral bleaching thresholds are defined by ${ }^{10}$ as SSTs $1^{\circ} \mathrm{C}$ higher than the highest monthly mean, placing the regional Maldives coral bleaching threshold at $\sim 30.90^{\circ} \mathrm{C}$, with ${ }^{11,12}$ denoting a similar bleaching threshold for Amphistegina at $31^{\circ} \mathrm{C}$ (Fig. 2).

The benthic foraminiferal genus Amphistegina lives on reefs at depths of $\leq 50 \mathrm{~m}$ and has a similar bleaching and thermal limit to corals, as well as a long (relative to other smaller foraminifera) life cycle (up to 12 months). On the contrary, within the top $\sim 100 \mathrm{~m}$ of the pelagic realm, live the smaller $(\sim<500 \mu \mathrm{m})$ symbiont-bearing, omnivorous, shallow-dwelling planktonic foraminiferal species (e.g., Globigerinoides ruber (white) and Trilobatus sacculifer) which can withstand greater temperature $\left(14-32^{\circ} \mathrm{C}\right)$ as well as salinity $(22-49 \mathrm{PSU})$ extremes ${ }^{13}$ and have a life cycle of usually 2-4 weeks. Importantly, planktonic foraminiferal shells are readily preserved within the sedimentary environment of the deeper pelagic ocean, adjacent to the shallow and often turbulent coral reef settings, which provides a more stable location whereby paleoenvironmental changes are potentially continuously recorded at high temporal resolution. Through geochemical analysis of the fossil shells of these planktonic species, with a predisposition to have lived within the warmest upper reaches of the water column due to the light dependency of their symbionts, we can extract the variability in temperature extrema for the tropical surface ocean, over temporal scales beyond that of modern-day instrumental records. In addition, due to their short life cycles, these planktonic species provide the potential to capture the temperature extremes experienced during brief periodic warm events, which would otherwise not be captured by studying larger benthic foraminifera or corals. As such, they provide the possibility to test how far beyond and how regularly bleaching thresholds, as observed in the modern, were exceeded during temperature maxima of past warmer interglacials.

While there might not be an ideal period of time, which inherently encapsulates our anthropogenically enhanced rapid warming trend, intervals with similar insolation patterns (e.g., MIS11c), and/or greater atmospheric $\mathrm{CO}_{2}$ levels (e.g., MIS9e) could be sufficient to observe variability in tropical SSTs in a world warmer than present. Within the last $500 \mathrm{kyr}$ of earth's history, MIS11 fits this profile, and is considered the closest warm period analogue to the Holocene $e^{6,7,14}$, due to its weak precessional forcing and similar insolation trends as well as its climatic extreme (MIS11c) being reportedly $0.21-5^{\circ} \mathrm{C}$ warmer ${ }^{15-18}$ (Fig. 3). The MIS9 interglacial, while possessing different astronomical forcings, its climatic extreme (MIS9e) is the second warmest over this period with the highest atmospheric $\mathrm{CO}_{2}$ levels ( 300 ppm) (Fig. 3).

Within this context, we have studied samples from the tropical Maldivian archipelago from MIS9e and MIS11c and compared them with the Recent environment (= mudline sample representing the last few hundred years, see "Methods" section) (exact sample locations are shown on Fig. 3e). Cores were retrieved from a depth of $487 \mathrm{~m}$ during the International Ocean Discovery Program (IODP) Expedition 359 from the Inner Sea of the Maldives archipelago; a low latitude, oligotrophic region $\left(3.2028^{\circ} \mathrm{N}, 73.2207^{\circ} \mathrm{E}\right)$ within the Indian Ocean ${ }^{19}$. The Maldives has extensive coral reef ecosystems, which includes both corals and larger benthic foraminiferal shoals, all of which were adversely impacted by all three of the recent mass-bleaching events.

Individual foraminiferal analysis (IFA) as well as traditional whole-shell (whole-test) analyses, based on pooled specimens, were conducted to measure the geochemical compositions $\left(\delta^{18} \mathrm{O}_{c}\right.$ and $\left.\mathrm{Mg} / \mathrm{Ca}\right)$ recorded in the calcitic shells of the two most commonly utilised (for surface ocean paleoreconstructions) shallow-dwelling, symbiont-bearing planktonic foraminiferal species: G. ruber (white) and T. sacculifer (with sac-like final chamber). We use these geochemical measurements, which have been extensively applied in paleoceanographic studies ${ }^{20-22}$, as proxies for SST and $\delta^{18} \mathrm{O}$ of seawater $\left(\delta^{18} \mathrm{O}_{\text {sw }}\right)$.

While traditional whole-shell measurements (based on 2-100 pooled specimens) provide indications of mean hydrographic conditions, IFA (based on the measurement of single specimens) has been previously used to study present and past seasonality and hydrographic variability ${ }^{20,23,24}$. We apply IFA to assess the temperature extrema, for Recent, MIS9e and MIS11c samples in relation to the modern-day coral bleaching-threshold $\left(\sim 30.90^{\circ} \mathrm{C}\right)$ for the Maldives region ${ }^{10,25}$. The rational to apply the IFA approach on planktonic foraminiferal species is based on their short life cycle (2-4 weeks) which implies that individual specimens live within or straddle the seasonal cycles. Thus, by measuring multiple specimens, the warmest (often short-lived) intervals can be captured and provide a window into how often and by what magnitude, the modern-day bleaching threshold was exceeded during the warmer MIS9e and MIS11c. This knowledge is essential to enhance predictability and understanding of the behaviour of bleaching susceptible organisms within coral reef ecosystems (e.g., corals and Amphistegina). Moreover, this insight is crucial given the future prospect of more frequent El Niño events, which will place these organisms at risk and under increasing strain, particularly in the case of the Maldives if SSTs continuously reach and surpass the local bleaching threshold of $\sim 30.90^{\circ} \mathrm{C}$ (Fig. 2b).

\section{Results}

Present and past SST extrema. Over the last 35 years, the maximum SST instrumentally recorded in the Maldives was $\sim 32.98{ }^{\circ} \mathrm{C}$, significantly beyond both the coral and Amphistegina bleaching thresholds, with the highest SSTs consistently recorded during El Niño events ${ }^{10}$ (Fig. 2b). The studied Amphistegina lessonii specimens, collected live (Rose Bengal stained) from surface sediments during the $2015 \mathrm{El}$ Niño, record a maximum temperature of $31.11^{\circ} \mathrm{C}\left(\right.$ mean $\left.=29.65 \pm 1.43^{\circ} \mathrm{C}\right)$ at the brink of its thermal tolerance $\left(31^{\circ} \mathrm{C}^{11,12}\right)$. These temperature calculations, derived from $\delta^{18} \mathrm{O}_{\mathrm{c}}$ signatures preserved in the calcitic shells, are comparable with in situ instrumentally recorded SST measurements (Fig. 2b). This attests to the reliability and applicability of foraminiferal geochemical proxies, which can rely on either $\delta^{18} \mathrm{O}_{c}$ or $\mathrm{Mg} / \mathrm{Ca}$ measurements, to calculate temperature estimates.

The long-term Antarctic dataset of ${ }^{16}$ shows a maximum higher latitude SST deviation of $+3.75^{\circ} \mathrm{C}$ and $+3.15^{\circ} \mathrm{C}$ at the peaks of MIS9e and MIS11c, in comparison to modern SSTs (Fig. 3). In contrast, the tropical alkenone SST stack of ${ }^{26}$ report a $\sim 1.52{ }^{\circ} \mathrm{C}$ and $\sim 1.70{ }^{\circ} \mathrm{C}$ increase, from modern SSTs, for each time interval with the MIS11 modelling study of ${ }^{15}$ showing only a $\sim 0.25-0.50{ }^{\circ} \mathrm{C}$ increase across the tropics. During extreme Pleistocene 


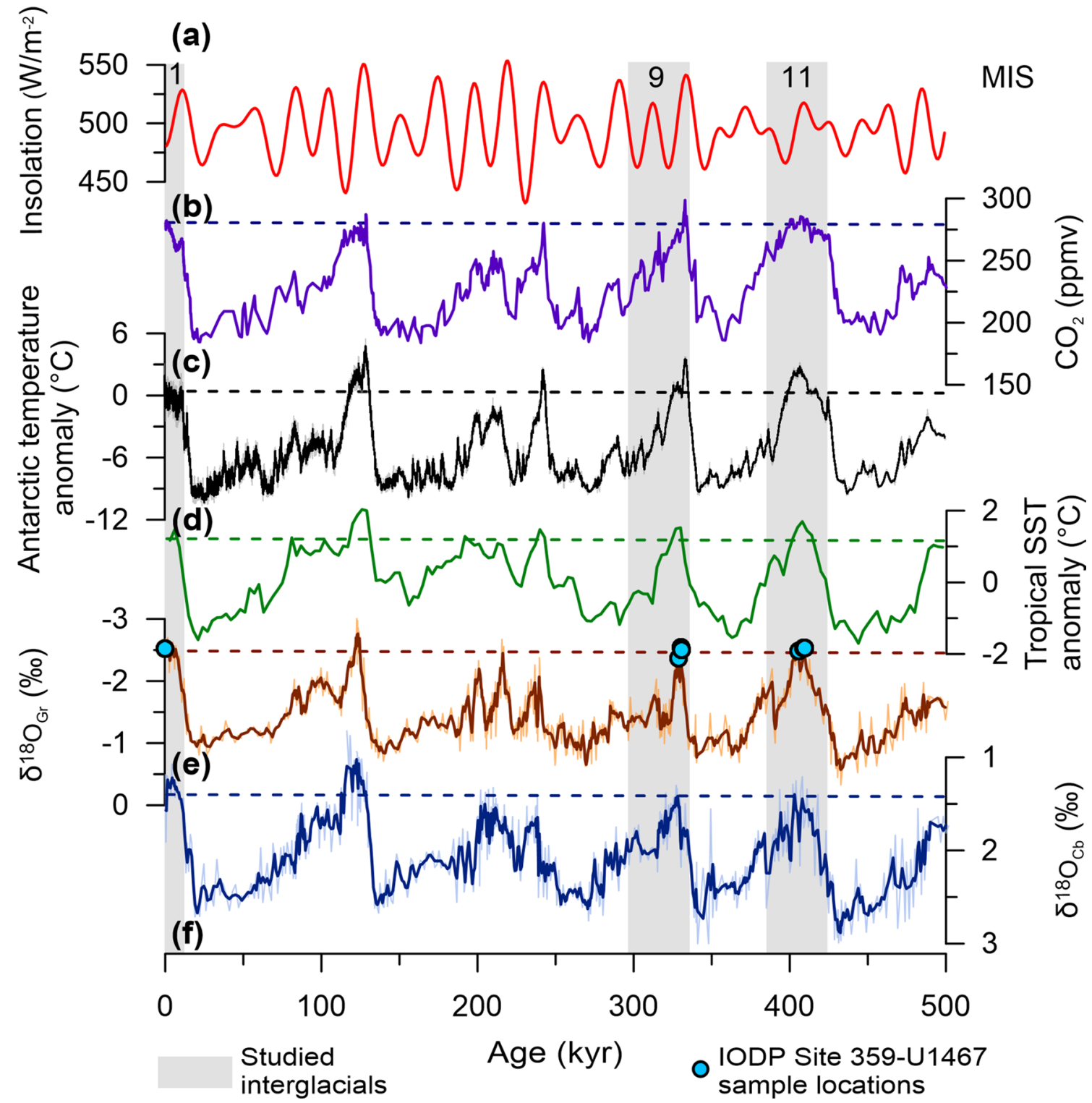

Figure 3. Long-term climatic records for the last $500 \mathrm{kyr}$. (a) Insolation patterns for $65^{\circ} \mathrm{N}^{64}$; (b) Compilation of atmospheric $\mathrm{CO}_{2}$ levels $^{14}$; (c) Antarctic temperature anomalies relative to mean temperature over the last millennium ${ }^{16,66}$; (d) Tropical $\mathrm{U}^{\mathrm{K}}{ }_{37}$ SST anomalies relative to their modern mean ${ }^{26,67}$; (e) Maldives (IODP Site 359-U1467) planktonic G. ruber $\delta^{18} \mathrm{O}_{c}$ record ${ }^{45,65}$ and (f) Maldives (IODP Site 359-U1467) epibenthic C. mabahethi $\delta^{18} \mathrm{O}_{c}$ record ${ }^{45,65}$. Dashed lines show the modern-day levels with the exact location of IODP Site 359-U1467 samples used in this study shown (blue circles). MIS = marine isotope stage with MIS1, MIS9 and MIS11 highlighted in grey shading, SST = sea surface temperature.

climatic excursions (e.g., during the warmer MIS9 and MIS11 interglacials) the tropics are anticipated to be more climatically stable in comparison to the higher latitudes, due to several feedback and/or thermostatic regulation mechanisms $s^{15,18,27}$. This dampened expression is similarly recorded by our traditional whole-shell (pooled) G. ruber (w) and T. sacculifer (w/s) geochemistry data $(\mathrm{Mg} / \mathrm{Ca})$, which record a mean temperature increase of only $\sim 0.45^{\circ} \mathrm{C}$ and $0.66^{\circ} \mathrm{C}$ for MIS9e and MIS 11c, respectively in comparison to the Recent (Fig. 4). Yet, these mean tropical seawater temperatures, recorded by G. ruber (w) $\left(\overline{\mathrm{x}}\right.$ Recent $=27.56 \pm 0.70{ }^{\circ} \mathrm{C}$; MIS9e $=27.59{ }^{\circ} \mathrm{C} \pm 2.08{ }^{\circ} \mathrm{C}$; MIS11c $\left.=27.82 \pm 0.64{ }^{\circ} \mathrm{C}\right)$ and $T$. sacculifer $(\mathrm{w} / \mathrm{s})\left(\overline{\mathrm{x}}\right.$ Recent $=24.33 \pm 0.45^{\circ} \mathrm{C}$; MIS9e $=25.21 \pm 2.40^{\circ} \mathrm{C}$; MIS11 $\mathrm{c}=25.38 \pm 1.39^{\circ} \mathrm{C}$ ), do not necessarily reflect the true upper temperature limits of the SML within which these species lived, as their living depths are governed by ecological preferences (Fig. 4). These symbiont-bearing and omnivorous species have a reported affinity for the deep chlorophyll maximum (DCM) with G. ruber (w) having a thermal preference of $\sim 27^{\circ} \mathrm{C}$ and T. sacculifer (w/s) known to live slightly deeper in cooler waters ${ }^{28-30}$. However, when compared with the widespread IFA $\delta^{18} \mathrm{O}_{c}$ data, it is evident that periodic extreme warm events are unlikely to be captured using the traditional whole-shell (pooled) geochemical methods (Fig. 4). 


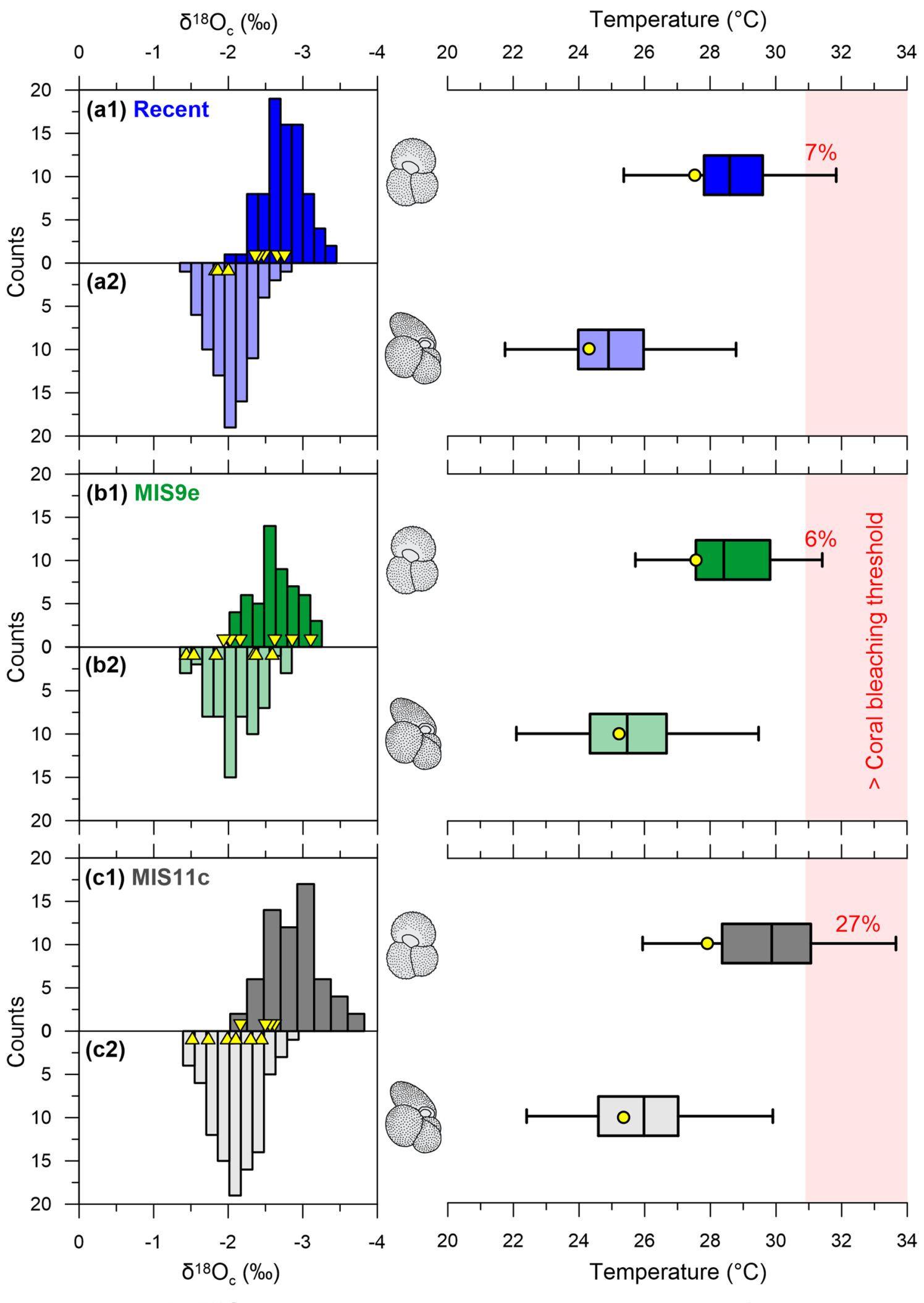

IFA $\delta^{18} \mathrm{O} /$ temperatures

$\Delta \nabla 0$ Traditional 'Pooled' $\bar{\delta}^{18} \mathrm{O} /$ temperatures

Figure 4. Spread in $\delta^{18} \mathrm{O}_{c}$ individual foraminiferal analysis (IFA) data and seawater temperature estimates. Histograms of the $\delta^{18} \mathrm{O}_{c}$ IFA data spread (counts = number of measurements) and the corresponding temperatures (box and whisker plots) for (a) the Recent (blue), (b) MIS9e (green) and (c) MIS11c (grey) for both (1) G. ruber (w) and (2) T. sacculifer (w/s). Traditional $\delta^{18} \mathrm{O}_{\mathrm{c}}$ values (based on pooled specimens) are shown (yellow triangles) for each sample together with the mean $\delta^{18} \mathrm{O}$ derived temperature (based on pooled specimens) (yellow circles). Temperatures $>$ the Maldives coral bleaching threshold $\left(\sim 30.9^{\circ} \mathrm{C}^{10}\right)$ are shown in red shading. Numbers indicate the percentage of the IFA temperature estimates, from each dataset, > this bleaching threshold. Note: MIS9e and MIS11c represent the pooled data from three samples. 
The Recent IFA G. ruber (w) temperature spread has an upper limit of $31.84{ }^{\circ} \mathrm{C}$, which is similar to the maximum SST recorded in the Maldives over the last six years $\left(=32.98^{\circ} \mathrm{C}\right)$, with $7 \%$ of the data above the modern-day coral bleaching threshold $\left(30.9^{\circ} \mathrm{C}\right)$. Comparable excursions were observed during MIS9e and MIS11c, with upper IFA temperature limits of $31.41^{\circ} \mathrm{C}$ and $33.66^{\circ} \mathrm{C}$, respectively. Furthermore, these IFA upper temperature limits are substantially warmer than the recorded means from the traditional pooled measurements (Fig. 4). More revealing than their upper limits, $6 \%$ and $27 \%$ of the MIS9e and MIS11c G. ruber (w) IFA temperature estimates are beyond the modern Maldivian coral bleaching threshold $\left(30.9^{\circ} \mathrm{C}\right)$. Overall, the T. sacculifer (w/s) data records cooler temperatures than G. ruber $(\mathrm{w})$, yet still illustrates an increase in the upper temperature extremes for both MIS9e and MIS11c in comparison to the Recent dataset. While the MIS9e datasets are not statistically different from the Recent, there is a significant difference with both the MIS11c G. ruber $(\mathrm{w})(\mathrm{t}=-4.1471, \mathrm{p}=0.000)$ and T. sacculifer $(\mathrm{w} / \mathrm{s})(\mathrm{t}=-3.3793, \mathrm{p}=0.001)$ datasets.

\section{Discussion}

Future insights and prospects. Increased thermal stress and its associated impacts, on tropical marine ecosystems, is a primary concern for the 21 st century. Over the last 100 years, SSTs have risen by more than $1^{\circ} \mathrm{C}$ within these ecologically sensitive areas ${ }^{4}$. Alarmingly, the rate of ocean warming is still expected to increase three to four-fold by the end of this century ${ }^{4}$. A warming climate will further promote more frequent as well as more severe El Niño events ${ }^{31}$, continuously pushing SSTs above coral and Amphistegina bleaching thresholds. These climatic projections may have disastrous effects on our coral reef ecosystems that are home to some of the highest biodiversity on earth and are extremely sensitive to thermal perturbations. Moreover, it is estimated that coral reefs contribute up to $\$ 37.8$ billion a year to the world's economy ${ }^{32}$. Thus aside from a biological viewpoint, protecting these ecosystems is vital for the economic survival of many countries, including the Maldives, who are reliant on them for both "on-reef" and "reef-adjacent" tourism.

Coral reefs and their associated benthic foraminiferal shoals are intrinsic ecological communities, made up of a wide array of fauna and flora, many of which are already living close-to or at their thermal limits ${ }^{33}$. Corals, sedentary marine animals and the building blocks within these tropical realms, and Amphistegina, an example genus of larger benthic foraminifera, are particularly vulnerable due to their reliance on symbionts and as such shallow habitats. Furthermore, due to the slow growth rates of corals $\left(0.3-10 \mathrm{~cm} / \mathrm{year}^{34}\right)$ protracted recovery times are evident following mass-bleaching events, which could prove detrimental, not only for corals but for tropical shallow water ecosystems as a whole. Thus, a future increase in frequency, magnitude and more importantly duration of periodic warm periods is of concern as it impedes the ability of both corals and Amphistegina to recover and this threat further supports the value of using past analogues to gain insight into possible future conditions.

Our novel application of the IFA technique highlights its potential in assessing temperature extrema. While the traditional (pooled) geochemical approach is favourable when constructing long-term records, as it ensures the data is less biased by outliers and presents a more representative mean for each time point, the variability in the data is lost. This demonstrates the applicability of the IFA technique if transgressions in the upper temperature limits are of interest, which is presently the primary threat for coral reef ecosystems. While our Recent and MIS9e datasets are similar and not statistically different, MIS11c is notable, clearly showing warmer SSTs. Considering it is the closest warm period analogue to the Holocene, within the last $500 \mathrm{kyr}$ of earth's history, it is a potential avenue to gain insights into future scenarios.

Our study on Maldivian, shallow-dwelling symbiont-bearing planktonic foraminifera confirms previous studies showing higher mean seawater temperatures in MIS11c $\left(+\sim 0.66^{\circ} \mathrm{C}\right)$ in comparison to the Recent. In addition to the mean populations sitting closer to the current coral bleaching threshold during MIS 11c, the IFA datasets specify a shift towards higher temperature extremes. Moreover, the MIS11c G. ruber (w) IFA dataset is skewed towards the lowest $\delta^{18} \mathrm{O}_{\mathrm{c}}$ /highest temperature values, implying an increase in periodic warming events (Fig. 4). Here we recognise the potential for IFA $\delta^{18} \mathrm{O}_{\mathrm{c}}$ datasets, to provide supplementary information from the traditional (pooled) foraminiferal geochemical analyses. As opposed to pooled measurements, which provide a mean signal of the measured population, it is possible to extract temperature extrema from IFA data and allows us to gain insights in the relative frequency and magnitude of periodic warm events. Based on the reality that current anthropogenic warming is much faster than seen during MIS11, more extreme as well as more frequent El Niño events are anticipated in the future ${ }^{31}$. Furthermore, we expect that the number of transgressions in the coral and Amphistegina bleaching thresholds will increase beyond that currently observed in both the Recent, MIS9e and MIS11c shallow water planktonic foraminiferal assemblages. As such, insight gained through IFA studies is invaluable given that thermal stress is already obvious today with an increasing number of global bleaching events, associated with high coral and Amphistegina mortality, over the last decades placing the world's coral reef ecosystems under ever increasing strain.

\section{Methods}

Study site and target foraminiferal species. The Maldivian archipelago is a partially drowned carbonate platform within the central, equatorial Indian Ocean. It consists of two rows of north-south orientated atolls, which encompass an Inner Sea. The lowermost neritic carbonate unit sits upon volcanic bedrock and has been dated back to the Eocene ${ }^{19}$ with continuous drift deposition, within the Inner Sea, starting 12.9 Ma at the establishment of the modern South Asian Monsoon (SAM) ${ }^{35,36}$. This seasonally reversing, major climatic system has an impact on both the regional precipitation patterns as well as physiochemical oceanographic properties (Fig. 1). The summer southwest SAM brings warm, wet conditions to the Indian subcontinent, as well as higher saline surface waters from the Arabian Sea into the Maldives region. In comparison, the winter northeast SAM results in cool, dry continental conditions and transports lower salinity water from the Bay of Bengal into the 
central, equatorial Indian Ocean. As a result, the Maldives seasonal salinity depth profiles can vary significantly, yet due to its tropical location the seasonal sea water temperatures are relatively stable.

Three symbiont-bearing foraminiferal species are used in this study: Amphistegina lessonii, Globigerinoides ruber (white) and Trilobatus sacculifer (with sac-like final chamber):

Amphistegina lessonii is a larger benthic, symbiont-bearing (diatoms) foraminiferal species. It has a shallow depth range $(0-50 \mathrm{~m})^{37-39}$ and is globally abundant in tropical coral reef, benthic foraminiferal shoal and general carbonate shelf settings ${ }^{40}$. Similarly to corals, amphisteginids have been shown to bleach under high temperatures/high irradiance levels with the new development of the Amphistegina Bleaching Index (ABI) as an indicator of photo-inhibitory stress in coral reef settings ${ }^{41,42}$. From $\sim 30^{\circ} \mathrm{C}$ this species starts showing signs of thermal stress, with bleaching and mortality reported for temperatures $>31^{\circ} \mathrm{C}^{11,12}$.

Globigerinoides ruber $(\mathrm{w})$ hosts dinoflagellate endosymbionts and is the most common planktonic foraminiferal species in tropical-subtropical waters ${ }^{13}$ state that while G. ruber (w) is generally considered one of the shallowest-dwelling species, its depth distribution does vary in relation to regional ecological conditions. It has a particular relation to the nutricline depth in less turbid, oligotrophic conditions ${ }^{43}$ which has been confirmed for the Maldives ${ }^{28}$. It is omnivorous, however in comparison to other omnivorous, symbiont-bearing species, it has demonstrated an elevated adaptation for consuming phytoplankton protein over zooplankton protein ${ }^{13}$. From culture experiments, it has a broad temperature $\left(14-31^{\circ} \mathrm{C}\right)$ and salinity $(22-49 \mathrm{PSU})$ tolerance, and has been reported as the most tolerant species to low sea surface salinity (SSS $)^{13}$. This species occurs year-round and has a fortnightly reproduction ${ }^{13}$.

Trilobatus sacculifer is a planktonic foraminiferal species abundant in tropical-subtropical surface waters and as such is extensively used in paleo-reconstructions. It hosts dinoflagellate endosymbionts yet is omnivorous, feeding predominantly on calanoid copepods ${ }^{13}$. It is a euryhaline species, with a broad salinity (24-47 PSU) and temperature $\left(14-32{ }^{\circ} \mathrm{C}\right)$ tolerance. Similarly to G. ruber $(\mathrm{w})$, this species occurs year-round and has a monthly reproduction on a synodic lunar cycle ${ }^{13}$. While a shallow dwelling species, it is generally reported to live slightly deeper in the water column, in comparison to G. ruber $(\mathrm{w})^{28,30,44}$.

Sampling. All planktonic foraminiferal specimens (G. ruber (w) and T. sacculifer (w/s)) for the geochemical analysis $\left(\delta^{18} \mathrm{O}_{\mathrm{c}}\right.$ and $\left.\mathrm{Mg} / \mathrm{Ca}\right)$ originate from the International Ocean Discovery Program (IODP) Expedition 359, Site U1467 ( $\left.4^{\circ} 51.0274^{\prime} \mathrm{N}, 73^{\circ} 17.0223^{\prime} \mathrm{E}\right)$ drilled in 2015 within the Inner Sea of the Maldivian archipelago at a water depth of $487 \mathrm{~m}^{19}$. The age model for these samples was adopted from a previous study ${ }^{45}$ which is based on the correlation of their long-term (0-1800 kyr) Site 359-U1467 C. mabahethi and G. ruber (w) $\delta^{18} \mathrm{O}_{\mathrm{c}}$ records to the stacked reference curve of ${ }^{46}$. Recent surface sediment samples (mudline A and B: representing the sample from the sediment/water interface), as well as three samples from the peak of MIS9e (U1467C, 2H6, 0-1 cm; U1467C, 2H6, 15-16 cm; U1467C, 2H6, 18-19 cm) and MIS11c (U1467B, 3H2, 147-148 cm; U1467B, 3H3, 9-10 cm; U1467B, 3H3, 12-13 cm) were analysed ${ }^{19,28}$ (sample locations are shown on Fig. 3). The mudline is identified as Recent, likely representing the last few hundred years, based on the presence of Rose Bengal ( $1 \mathrm{~g} / \mathrm{L})$ stained ostracods and benthic foraminifera. The study by ${ }^{45}$ has verified that diagenetic influences, within this shallow, carbonate environment, are not a concern for foraminiferal geochemical compositions over the investigated time-interval (MIS1-11).

Rose Bengal stained A. lessonii specimens were obtained from modern surface rubble samples collected by hand, at $10 \mathrm{~m}$ water depth, during the 2015 International Union for Conservation of Nature (IUCN) REGENERATE cruise $^{47}$ (Supplementary Table 6). Samples were collected from the reefs of two islands, Maayafushi and Rasdhoo, both located within the central part of the Maldivian archipelago. As the foraminifera shells were stained pink, it implies they were living at the time of collection. These specimens were used for stable isotopic analysis and their reconstructed temperatures represent modern (a cumulative signal encompassing their lifespan of four to twelve months ${ }^{48}$ ) conditions (Supplementary Tables 5-6). A full explanation of the Rose Bengal protein stain for foraminifera is detailed in ${ }^{49}$.

$\delta^{18} \mathrm{O}_{\mathrm{c}}$ stable isotopic analysis. All samples were initially washed using a $32 \mu \mathrm{m}$ sieve to remove the finer clay and silt fractions. Subsequently, they were air dried and sieved into discrete sizes for foraminiferal picking. To ensure enough calcite for the measurements, all specimens for Individual Foraminifera Analysis (IFA) for both G. ruber $(\mathrm{w})$ and T. sacculifer $(\mathrm{w} / \mathrm{s})(\mathrm{n}=632)$ were picked from the $355-400 \mu \mathrm{m}$ size fraction. In addition, traditional whole-shell (pooled) measurements for G. ruber $(\mathrm{w})(\mathrm{n}=24)$ were conducted on specimens from the $212-400 \mu \mathrm{m}$ fraction ( $2-5$ pooled specimens). Trilobatus sacculifer $(\mathrm{w} / \mathrm{s})$ traditional whole-shell analysis $(\mathrm{n}=21)$ was measured on specimens ( 2 pooled specimens) from the $300-355 \mu \mathrm{m}$ fraction. The majority of these pooled measurements are obtained from ${ }^{28,45,50,51}$ (Supplementary Table 1). Amphistegina lessonii measurements were run on single specimens $>250 \mu \mathrm{m}$ in size. Prior to stable isotopic analysis, all shells were briefly cleaned (1-2 s) by ultrasonication in Milli-Q water to remove any adhering particles. All stable isotopic measurements were conducted at the School of GeoSciences at the University of Edinburgh on a Thermo Electron Delta + Advantage mass spectrometer integrated with a Kiel carbonate III automated extraction line. Samples were reacted with $100 \%$ phosphoric acid $\left(\mathrm{H}_{3} \mathrm{PO}_{4}\right)$ at $90{ }^{\circ} \mathrm{C}$ for $15 \mathrm{~min}$, with the evolved $\mathrm{CO}_{2}$ gas collected in a liquid nitrogen coldfinger and analysed compared to a reference gas. All samples are corrected using an internal laboratory standard and expressed as parts per mil (\%) relative to Vienna Pee Dee Belemnite (VPDB). Replicate measurements of the standards give the instrument an analytical precision $(1 \sigma)$ of $\sim 0.05 \%$ for $\delta^{18} \mathrm{O}$ and $\delta^{13} \mathrm{C}$.

Mg/Ca analysis. The Mg/Ca data is obtained from ${ }^{28,45,50,51}$ (Supplementary Table 1). Each G. ruber (w) Mg/ Ca analysis $(n=17 ; 212-250 \mu \mathrm{m}$ in size) was conducted on 30 pooled specimens by inductively coupled plasma optical emission spectrometry (ICP-OES) on a Thermoscientific iCap 6300 (dual viewing) at the Institute of 
Geosciences of the Goethe-University of Frankfurt. All samples were initially cleaned (1-2 s) by ultrasonication in Milli-Q water and then the standard oxidative cleaning protocol of ${ }^{52}$ followed to prevent clay mineral contamination. The final centrifuged sample solution was diluted with an yttrium solution $(1 \mathrm{mg} / \mathrm{l})$ prior to measurement to allow for the correction of matrix effects. In addition, before each analysis five calibration solutions were measured to allow for intensity ratio calibrations. All element/Ca measurements were standardized using an internal consistency standard (ECRM 752-1, $3.761 \mathrm{mmol} / \mathrm{mol} \mathrm{Mg} / \mathrm{Ca}$ ). Furthermore, the elements $\mathrm{Al}$, $\mathrm{Fe}$, and $\mathrm{Mn}$ were screened and blanks periodically run to monitor for further signs of contamination during the analyses.

Establishment of present and past seawater temperatures. Prior to temperature calculations, we test the IFA distributions for normality using the Shapiro-Wilk test and the Fisher-Pearson coefficient of skewness with bootstrap confidence intervals, to define the skewness of the datasets ${ }^{33}$ (Supplementary Table 3 ). The Recent G. ruber (w) and T. sacculifer (w/s) and MIS11c T. sacculifer are normally distributed. In the case of both MIS9e datasets and the MIS11c G. ruber population, the null hypothesis that the data are normally distributed $(\mathrm{p} \leq 0.05)$ is rejected (Supplementary Table 3$)$. Considering bioturbation within the sediment record is a possibility, we use two methods to identify and remove outliers in the IFA datasets. Firstly, the inter-quartile range (IQR) is used for each $\delta^{18} \mathrm{O}_{c}$ dataset, which defines a measurement as an outlier if it falls outside the range [Q1-1.5 (Q3 - Q1), Q3 + 1.5 (Q3 - Q1)], with IQR=Q3-Q1 and Q3 and Q1 representing the third and first quartile of the dataset ${ }^{20}$. But if there is considerable reworking, the IQR method would not necessarily identify reworked glacial measurements (highest $\delta^{18} \mathrm{O}_{c}$ values) within the interglacial samples. As such, the Recent IFA datasets, which are both normally distributed, are used to further set a rudimentary cut-off point for the highest $\delta^{18} \mathrm{O}_{c}$ (=lowest temperatures) value to expect during past interglacial minima periods for both G. ruber (w) and T. sacculifer (w/s) (this is discussed further in the Supplementary Materials, Supplementary Figs. 1-3).

There are innumerable analytical techniques (e.g., traditional mass spectrometry, secondary-ion mass spectrometry, laser ablation inductively coupled plasma mass spectrometry), proxies $\left(\mathrm{Mg} / \mathrm{Ca}, \delta^{18} \mathrm{O}\right.$, clumped isotopes, TEX86, $\mathrm{U}^{\mathrm{k}}{ }_{37}$ ) as well as target medians (e.g., calcitic shells of foraminifera, aragonitic coral skeletons, ice, lipids, alkenones) which are used in marine paleo-temperature reconstructions. Furthermore, different methods exist in the literature to calculate temperature estimates using both planktonic foraminiferal $\delta^{18} \mathrm{O}_{\mathrm{c}}$ and $\mathrm{Mg} / \mathrm{Ca}$ measurements with innumerable species-specific $\delta^{18} \mathrm{O}$-temperature and $\mathrm{Mg} / \mathrm{Ca}$-temperature equations reported ${ }^{20,23,30,54-56}$. Moreover, due to the exponential nature of the $\mathrm{Mg} / \mathrm{Ca}$-temperature equations, if inappropriately applied, offsets in the upper temperature range are exacerbated. Additional considerations are speciesspecific offsets and differential geochemical compositions within the shell (e.g., high versus low Mg banding, gametogenic calcite). Trilobatus sacculifer gametogenic calcite has been reported to be significantly enriched in $\mathrm{Mg}$ in comparison to the rest of the shell ${ }^{57}$. As T. sacculifer specimens selected for use in this study underwent reproduction, indicated by the presence of a sac-like final chamber ${ }^{58}$, we can expect their $\mathrm{Mg} / \mathrm{Ca}$ ratios to be biased. As such, to avoid overestimates we chose to use only $G$ ruber (w, pooled) $\mathrm{Mg} / \mathrm{Ca}$ and $\delta^{18} \mathrm{O}_{\mathrm{c}}$ data to calculate representative $\delta^{18} \mathrm{O}_{\mathrm{sw}}$ values for each time interval, for use with both the G. ruber $(\mathrm{w})$ and T. sacculifer (w/s) $\delta^{18} \mathrm{O}_{c}$ IFA datasets. Considering both planktonic species are considered as shallow-dwellers with similar living depths and an affinity for the DCM, the utilisation of common $\delta^{18} \mathrm{O}_{\text {sw }}$ values is applicable ${ }^{13,28,30}$.

The G. ruber $\mathrm{Mg} / \mathrm{Ca}$-temperature Eq. (1) from ${ }^{55}$ (temperature calibration range: $\sim 22-27^{\circ} \mathrm{C}$ ), similarly applied in the Maldivian study of ${ }^{28}$, was used in this study:

$$
M g / C a=0.34( \pm 0.08) \exp (0.102( \pm 0.010) * \mathrm{~T})
$$

The applied $\delta^{18} \mathrm{O}$-temperature species-specific equations (Eqs. 2 and 3) were previously utilised in the local study by ${ }^{28}$. Both the G. ruber (Eq. 2) and T. sacculifer (Eq. 3) equations are from the Indian Ocean study of ${ }^{59}$ (temperature calibration range: $\sim 20-31^{\circ} \mathrm{C}$ ):

$$
\begin{gathered}
T=12.75-5\left(\delta^{18} O_{c}-\delta^{18} O_{s w}\right) \\
T=11.95-5.26\left(\delta^{18} O_{c}-\delta^{18} O_{s w}\right)
\end{gathered}
$$

Using the above equations, the range in temperature estimates are obtained as follows (Fig. 4):

1. The mean G. ruber (w) Mg/Ca measurements are used together with Eq. (1) to calculate a temperature estimate for each time point (Supplementary Table 1). Since the $\mathrm{Mg} / \mathrm{Ca}$ calcification temperatures are based on 30 pooled specimens, they are considered to reflect mean calcification temperatures.

2. The $\mathrm{Mg} / \mathrm{Ca}$ derived temperature estimates are then used together with the mean traditional (pooled) G. ruber $(\mathrm{w}) \delta^{18} \mathrm{O}_{\mathrm{c}}$ data and Eq. (2) to calculate representative $\delta^{18} \mathrm{O}_{\mathrm{sw}}$ values for each time point (Supplementary Table 2). As these are calculated from pooled samples, they are considered to mirror mean $\delta^{18} \mathrm{O}_{\mathrm{sw}}$ values for both the Recent and fossil populations.

3. The G. ruber (w) and T. sacculifer (w/s) IFA datasets are then used, together with the relevant species-specific $\delta^{18} \mathrm{O}$-temperature equations and $\delta^{18} \mathrm{O}_{\mathrm{sw}}$ values, to calculate the spread in temperature estimates (Fig. 4, Supplementary Tables 3-4).

Trilobatus sacculifer (w/s) data from the glacial maxima of MIS12 are included in the study to illustrate the applicability of the IFA method, however, as they do not contribute to the discussion on bleaching thresholds, they are discussed further in the Supplementary Materials (Supplementary Figs. 1, 3). 
Finally, the temperature estimates for the shallow-dwelling symbiont-bearing benthic A. lessonii are obtained using the genus-specific $\delta^{18} \mathrm{O}$-temperature equation of ${ }^{60}$ (Eq. 4) (Supplementary Tables 5-6).

$$
T=16.3-4.24\left(\delta^{18} O_{c}-\delta^{18} O_{s w}\right)
$$

Considering the benthic specimens were deemed living at the time of collection (Rose Bengal stained), a mean regional surface $(0 \mathrm{~m}) \delta^{18} \mathrm{O}_{\mathrm{sw}}$ value $\left(0.49 \%\right.$ ) is used together with the $\delta^{18} \mathrm{O}_{\mathrm{c}}$ data in the calculations (Supplementary Tables 5-6).

\section{Data availability}

All new raw IFA data has been made available on The World Data Center PANGAEA.

Received: 3 April 2020; Accepted: 28 April 2021

Published online: 13 May 2021

\section{References}

1. Baker, A. C., Glynn, P. W. \& Riegl, B. Climate change and coral reef bleaching: An ecological assessment of long-term impacts, recovery trends and future outlook. Estuar. Coast. Shelf Sci. 80, 435-471 (2008).

2. Carpenter, K. E. et al. One-third of reef-building corals face elevated extinction risk from climate change and local impacts. Science (80-. ). 321, 560-563 (2008).

3. NOAA. Coral Reef Conservation Program (2018).

4. IPCC. Climate Change 2013: The Physical Science Basis: Contribution of Working Group I to the Fourth Assessment Report of the Intergovernmental Panel on Climate Change. (Cambridge University Press, 2013).

5. Langer, M. R., Silk, M. T. \& Lipps, J. H. Global ocean carbonate and carbon dioxide production; the role of reef Foraminifera. J. Foraminifer. Res. 27, 271-277 (1997).

6. Past Interglacials Working Group of PAGES. Interglacials of the last 800,000 years. Rev. Geophys. 54, 162-219 (2016).

7. Candy, I., Schreve, D. C., Sherriff, J. \& Tye, G. J. Marine isotope stage 11: Palaeoclimates, palaeoenvironments and its role as an analogue for the current interglacial. Earth-Sci. Rev. 128, 18-51 (2014).

8. Glynn, P. W. Coral reef bleaching: ecological perspectives. Coral Reefs 12, 1-17 (1993).

9. Glynn, P. W. Coral reef bleaching: Facts, hypotheses and implications. Glob. Chang. Biol. 2, 495-509 (1996).

10. NOAA. NOAA Coral Reef Watch. https://coralreefwatch.noaa.gov/satellite/methodology/methodology.p.

11. Schmidt, C., Heinz, P., Kucera, M. \& Uthicke, S. Temperature-induced stress leads to bleaching in larger benthic foraminifera hosting endosymbiotic diatoms. Limnol. Oceanogr. 56, 1587-1602 (2011).

12. Uthicke, S., Vogel, N., Doyle, J., Schmidt, C. \& Humphrey, C. Interactive effects of climate change and eutrophication on the dinoflagellate-bearing benthic foraminifer Marginopora vertebralis. Coral Reefs 31, 401-414 (2012).

13. Schiebel, R. \& Hemleben, C. Planktic Foraminifers in the Modern Ocean. (Springer, 2017).

14. Lüthi, D. et al. High-resolution carbon dioxide concentration record 650,000-800,000 years before present. Nature 453, 379-382 (2008).

15. Milker, Y. et al. Global and regional sea surface temperature trends during marine isotope stage 11. Clim. Past. 9, 2231-2252 (2013).

16. Jouzel, J. et al. Orbital and millennial antarctic climate variability over the past 800,000 years. Science (80-. ). 317, 793-796 (2007).

17. Emeis, K. C., Anderson, D. M., Doose, H., Kroon, D. \& Schulz-Bull, D. Sea-surface temperatures and the history of monsoon upwelling in the northwest Arabian Sea during the last 500,000 years. Quatern. Res. 43, 355-361 (1995).

18. Alonso-García, M. et al. Sea-surface temperature, productivity and hydrological changes in the Northern Indian Ocean (Maldives) during the interval 575-175 ka (MIS 14 to 7). Palaeogeogr. Palaeoclimatol. Palaeoecol. 536, 109376 (2019).

19. Betzler, C. et al. Proceedings of the International Ocean Discovery Program Vol. 359. (International Ocean Discovery Program, 2017).

20. Ganssen, G. M. et al. Quantifying sea surface temperature ranges of the Arabian Sea for the past 20000 years. Clim. Past. 7, 1337-1349 (2011)

21. Metcalfe, B., Feldmeijer, W. \& Ganssen, G. M. Oxygen isotope variability of planktonic foraminifera provide clues to past upper ocean seasonal variability. Paleoceanogr. Paleoclimatol. 34, 374-393 (2019).

22. Raddatz, J., Nürnberg, D., Tiedemann, R. \& Rippert, N. Southeastern marginal West Pacific Warm Pool sea-surface and thermocline dynamics during the Pleistocene (2.5-0.5 Ma). Palaeogeogr. Palaeoclimatol. Palaeoecol. 471, 144-156 (2017).

23. Groeneveld, J., Ho, S. L., Mackensen, A., Mohtadi, M. \& Laepple, T. Deciphering the variability in Mg/Ca and stable oxygen isotopes of individual foraminifera. Paleoceanogr. Paleoclimatol. 34, 755-773 (2019).

24. Fritz-Endres, T., Dekens, P. S., Fehrenbacher, J., Spero, H. J. \& Stine, A. Application of individual foraminifera $\mathrm{Mg} / \mathrm{Ca}$ and $\delta^{18} \mathrm{O}$ analyses for paleoceanographic reconstructions in active depositional environments. Paleoceanogr. Paleoclimatol. 34, 1610-1624 (2019).

25. Perry, C. T. \& Morgan, K. M. Bleaching drives collapse in reef carbonate budgets and reef growth potential on southern Maldives reefs. Sci. Rep. 7, 1-9 (2017).

26. Herbert, T. D., Peterson, L. C., Lawrence, K. T. \& Liu, Z. Tropical ocean temperatures over the past 3.5 million years. Science (80-. ). 328, 1530-1534 (2010).

27. Miller, R. L. Tropical thermostats and low cloud cover. J. Clim. 10, 409-440 (1997).

28. Stainbank, S. et al. Controls on planktonic foraminifera apparent calcification depths for the northern equatorial Indian Ocean. PLoS One 14, e0222299 (2019).

29. Mulitza, S., Wolff, T., Pätzold, J., Hale, W. \& Wefer, G. Temperature sensitivity of planktic foraminifera and its influence on the oxygen isotope record. Mar. Micropaleontol. 33, 223-240 (1998).

30. Rippert, N. et al. Constraining foraminiferal calcification depths in the western Pacific warm pool. Mar. Micropaleontol. 128, 14-27 (2016).

31. Wang, B. et al. Historical change of El Niño properties sheds light on future changes of extreme El Niño. Proc. Natl. Acad. Sci. USA 116, 22512-22517 (2019).

32. Spalding, M. D., Brumbaugh, R. D. \& Landis, E. Atlas of Ocean Wealth. The Nature Conservancy (2016).

33. Smith, R. D. S. et al. Thermal biases and vulnerability to warming in the world's marine fauna. Nature 1-17 (2015).

34. Barnes, R. Invertebrate Zoology. (Harcourt Brace JOvanoch College Publishers, 1987).

35. Betzler, C. et al. The abrupt onset of the modern South Asian monsoon winds. Sci. Rep. 6, 29838 (2016).

36. Bialik, O. M., Frank, M., Betzler, C., Zammit, R. \& Waldmann, N. D. Two-step closure of the Miocene Indian Ocean gateway to the mediterranean. Sci. Rep. 9, 1-10 (2019).

37. Murray, J. W. Ecology and Applications of Benthic Foraminifera. (Cambridge University Press, 2006).

38. Hohenegger, J. Depth estimation by proportions of living larger foraminifera. Mar. Micropaleontol. 26, 31-47 (1995). 
39. Hohenegger, J. Estimation of environmental paleogradient values based on presence/absence data: A case study using benthic foraminifera for paleodepth estimation. Palaeogeogr. Palaeoclimatol. Palaeoecol. 217, 115-130 (2005).

40. Langer, M. R. \& Hottinger, L. Biogeography of selected 'larger' foraminifera. Micropaleontology 46, 105-126 (2000).

41. Hallock, P., Williams, D. E., Fisher, E. M. \& Toler, S. K. Bleaching in foraminifera with algal symbionts: Implications for reef monitoring and risk assessment. Anu. Inst. Geocienc. 29, 108-128 (2006).

42. Spezzaferri, S., El Kateb, A., Pisapia, C. \& Hallock, P. In situ observations of foraminiferal bleaching in the Maldives, Indian Ocean. J. Foraminifer. Res. 48, 75-84 (2018).

43. Schiebel, R. et al. Distribution of diatoms, coccolithophores and planktic foraminifers along a trophic gradient during SW monsoon in the Arabian Sea. Mar. Micropaleontol. 51, 345-371 (2004).

44. Birch, H., Coxall, H. K., Pearson, P. N., Kroon, D. \& O’Regan, M. Planktonic foraminifera stable isotopes and water column structure: Disentangling ecological signals. Mar. Micropaleontol. 101, 127-145 (2013).

45. Stainbank, S. et al. Assessing the impact of diagenesis on foraminiferal geochemistry from a low latitude, shallow-water drift deposit. Earth Planet. Sci. Lett. 116390 (2020).

46. Ahn, S., Khider, D., Lisiecki, L. E. \& Lawrence, C. E. A probabilistic Pliocene-Pleistocene stack of benthic $\delta^{18} \mathrm{O}$ using a profile hidden Markov model. Dyn. Stat. Clim. Syst. 2, 1-16 (2017).

47. Pisapia, C. et al. Baseline Assessment of Coral Reefs of North Ari Atoll, Maldives. https://portals.iucn.org/library/sites/library/files/ documents/2017-017_0.pdf (IUCN and Government of Maldives, 2017).

48. Hallock, P., Talge, H. K., Cockey, E. M. \& Muller, R. G. A new disease in reef-dwelling foraminifera: Implications for coastal sedimentation. J. Foraminifer. Res. 25, 280-286 (1995).

49. Bernhard, J. M. Distinguishing live from dead foraminifera: Methods review and proper applications. Micropaleontology 46, 38-46 (2000).

50. Stainbank, S., Spezzaferri, S., Kroon, D., de Leau, E. S. \& Rüggeberg, A. The Planktonic foraminifera Globigerinoides eoconglobatus n. sp. in a glacial-interglacial context: IODP359 Sites U1467 and U1468. Swiss J. Geosci. 111, 483-494 (2018).

51. Stainbank, S. et al. Monsoon and tropical climate forcing on the physicochemical and thermocline characteristics of the Maldives Inner Sea: Insights from Marine Isotope stages 1-2 and 10-13. Paleoceanogr. Paleoclimatol. (accepted).

52. Barker, S., Greaves, M. \& Elderfield, H. A study of cleaning procedures used for foraminiferal Mg/Ca paleothermometry. Geochem. Geophys. Geosyst. 4, 8407 (2003).

53. Shapiro, S. S. \& Wilk, M. B. An analysis of variance test for normality (complete samples). Biometrika 52, 591-611 (1965).

54. Ravelo, A. C. \& Hillaire-Marcel, C. The use of oxygen and carbon isotopes of foraminifera in paleoceanography. Dev. Mar. Geol. 1, 735-764 (2007).

55. Anand, P., Elderfield, H. \& Conte, M. H. Calibration of Mg/Ca thermometry in planktonic foraminifera from a sediment trap time series. Paleoceanography 18, 1050 (2003).

56. Mulitza, S. et al. Temperature: $\delta^{18} \mathrm{O}$ relationships of planktonic foraminifera collected from surface waters. Palaeogeogr. Palaeoclimatol. Palaeoecol. 202, 143-152 (2003).

57. Nürnberg, D., Bijma, J. \& Hemleben, C. Assessing the reliability of magnesium in foraminiferal calcite as a proxy for water mass temperatures. Geochim. Cosmochim. Acta 60, 803-814 (1996).

58. Bé, A. W. H., Anderson, O. R., Faber, W. W., Caron, D. A. \& Be, A. W. H. Sequence of morphological and cytoplasmic changes during gametogenesis in the planktonic foraminifer Globigerinoides sacculifer (Brady). Micropaleontology 29, 310 (1983).

59. Duplessy, J. C., Bé, A. W. H. \& Blanc, P. L. Oxygen and carbon isotopic composition and biogeographic distribution of planktonic foraminifera in the Indian Ocean. Palaeogeogr. Palaeoclimatol. Palaeoecol. 33, 9-46 (1981).

60. Saraswati, P. K. et al. $\delta^{18} \mathrm{O}$ of Larger benthic foraminifera: Temperature calibration for shallow marine tropical-subtropical carbonates. In Micropaleontology and Its Applications (eds. Kathal, P. K., Nigam, R. \& Talib, A.) 59-70 (Scientific Publishers, 2018).

61. UNEP-WCMC, WorldFish Centre, WRI, T. Global distribution of warm-water coral reefs, compiled from multiple sources including the Millennium Coral Reef Mapping Project. Version 4.0. Includes contributions from IMaRS-USF and IRD (2005), IMaRS-USF (2005) and Spalding et al. (2001). http://data.unep-wcmc.org/datasets/1. (U. Cambridge, 2010).

62. Schlitzer, R. Ocean Data View. (2018).

63. Zweng, M. M. et al. World ocean atlas 2013, Vol. 2. Salinity. In NOAA Atlas NESDIS 74 (ed. Levitus, S.) Vol. 39 (U.S. Gov. Print. Off., 2013).

64. Laskar, J. et al. A long-term numerical solution for the insolation quantities of the Earth. Astron. Astrophys. 428, 261-285 (2004).

65. Stainbank, S. et al. Long-term, high-resolution foraminiferal geochemical records $\left(\delta^{18} \mathrm{O}, \delta^{12} \mathrm{C}\right)$ from IODP Site 359-U1467. PANGAEA. https://doi.org/10.1594/PANGAEA.914883 (2020).

66. Jouzel, J. \& Masson-Delmotte, V. EPICA Dome C Ice Core 800KYr deuterium data and temperature estimates. PANGAEA. https:// doi.org/10.1594/PANGAEA.683655 (2007).

67. Herbert, T. D., Peterson, L. C., Lawrence, K. T. \& Liu, Z. Tropical SSTs over the past 3.5 million years. PANGAEA. https://doi.org/ 10.1594/PANGAEA.874752 (2017).

\section{Acknowledgements}

This work was funded by the Swiss National Science Foundation (SNSF) through grant number 200021_165852/1 awarded to S.Sp. Additionally DK acknowledges funding support from the Natural Environment Research Council (NERC) through grant number NERC-NE/N012739/1. The authors would like to thank the International Ocean Discovery Program (IODP) for supplying the samples used in this study. Both Colin Chilcott, from the University of Edinburgh, and Dr. Jacek Raddatz, from the Goethe-University of Frankfurt are thanked for their help with the stable isotopic and $\mathrm{Mg} / \mathrm{Ca}$ measurements. The image of a bleached coral in Fig. 2a is credited to The Ocean Agency/ XL Catlin Seaview Survey and Richard Vevers/The Ocean Agency and the living coral image to Dr. Marine Fau from the University of Fribourg.

\section{Author contributions}

S.St. performed the study, analysed the results and led the writing of this work. D.K. performed the study, analysed the results, contributed in discussion, and helped shape the writing of the manuscript. E.S.L. performed the study, analysed the results and helped shape the writing of the manuscript. S.Sp. contributed in discussion and helped shape the research, analysis, and writing of the manuscript.

\section{Competing interests}

The authors declare no competing interests. 


\section{Additional information}

Supplementary Information The online version contains supplementary material available at https://doi.org/ 10.1038/s41598-021-89697-0.

Correspondence and requests for materials should be addressed to S.S.

Reprints and permissions information is available at www.nature.com/reprints.

Publisher's note Springer Nature remains neutral with regard to jurisdictional claims in published maps and institutional affiliations.

(c) (i) Open Access This article is licensed under a Creative Commons Attribution 4.0 International License, which permits use, sharing, adaptation, distribution and reproduction in any medium or format, as long as you give appropriate credit to the original author(s) and the source, provide a link to the Creative Commons licence, and indicate if changes were made. The images or other third party material in this article are included in the article's Creative Commons licence, unless indicated otherwise in a credit line to the material. If material is not included in the article's Creative Commons licence and your intended use is not permitted by statutory regulation or exceeds the permitted use, you will need to obtain permission directly from the copyright holder. To view a copy of this licence, visit http://creativecommons.org/licenses/by/4.0/.

(C) The Author(s) 2021 